\title{
Professional ethics: on transmitting complaints to one's colleagues
}

\author{
Raanan Gillon Imperial College, St Mary's Hospital Medical School, and King's College, London University
}

What ought a doctor to do when he or she suspects a colleague may have behaved badly to a patient? This is a question which arises from time to time in any doctor's practice and is, it is probably safe to assert, often evaded rather than confronted. Part of the problem is that doctors are educated and trained to have not only a strong sense of obligation to their patients but also a strong sense of collegiality with other doctors, so that any sort of disparagement or apparent disparagement of medical colleagues is disapproved of. The tradition is a long one, stemming from Hippocratic times and to this day guidance in the General Medical Council (GMC)'s 'little blue book' on professional conduct states, under the heading 'Disparagement of professional colleagues': 'It is improper for a doctor to disparage, whether directly or by implication, the professional skill, knowledge, qualifications or services of any other doctor, irrespective of whether this may result in his own professional advantage, and such disparagement may raise a question of serious professional misconduct'(1). It should immediately be added that the next two paragraphs modify this uncompromising paragraph 65 , allowing doctors to disagree with the advice and treatment offered by other doctors, allowing them to advise patients to seek other sources of medical care where they believe that this would be in the patient's best interests and allowing, indeed requiring doctors to inform an appropriate body about a professional colleague whose behaviour may have raised a question of serious professional misconduct, or whose fitness to practise may be seriously impaired by reason of a physical or mental condition'.

Mrs Jean Robinson, one of the non-medical members of the GMC, wishes to have paragraph 65 deleted, and the Standards Committee of the GMC have agreed that she has raised an important issue - notably that there is a risk that the paragraph may discourage doctors from making constructive criticisms, in good faith, of other doctors, or from reporting a colleague's perceived misbehaviour to official bodies. While the Standards Committee does not yet feel ready either simply to recommend removal of paragraph 65 or to propose revised guidance, a move towards change has begun. Thus in its latest (and much brighter) annual report (2) the GMC states that it is considering the general issue of complaints and criticisms that fall short of serious professional misconduct but which do allege that a doctor's professional practice has fallen below acceptable standards. The issue is to be considered in the context of new advice on performance review procedures which the GMC is developing, which it will first discuss with patient organisations and with the medical profession and for which it will then propose amendments to the Medical Act.

In what circumstances might it be justified to 'disparage' another doctor (though 'criticise' would be a better term than 'disparage' which is ambiguous between unjustified discrediting or criticism of anothep and mere discrediting or criticism of another, whethes or not justified)?

The most obvious cases arise where a patient is seriously endangered or in some way seriously harmed or wronged by another doctor. In such cases there is no doubt that the GMC has imposed a duty on doctors to report such behaviour 'to an appropriate body'. What, however, about cases where the conduct of another doctor does not amount to what the GMC classifies as 'serious professional misconduct' (what it used to call 'infamous conduct in a professional respect') but nonetheless either causes unnecessary harm or discomfort - or risk of harm or discomfort - to a patient or unnecessarily distresses a patient? Surely in such cases it may often, perhaps usually, be justified at least to bring the matter to the attention of the doctor concerned and invite his or her comments.

Whether or not the GMC abolishes or modifies the offending paragraph 65 , a fundamental problem would remain. Doctors tend to dislike complaining about each $N$ other or even passing on complaints about each other not only do they tend to feel disloyal, but the process tends to be unpleasant, embarrassing, and all too easily leads to the reputation of trouble-maker. A second problem is that complaints from patients about other doctors are not necessarily justified - the doctorpatient relationship is often set in circumstances which for both parties, but especially for patients, may be emotionally highly charged: in such circumstances it is easy for inappropriate or disproportionate hostility and anger to be evoked and then projected onto the doctor (by the same token such highly emotionally charged circumstances can also evoke deep feelings of 
disproportionate gratitude, devotion or admiration from patients!). A third problem is the worry that passing on a complaint will only aggravate any problem existing between the patient and the complained-about doctor and lead to more harm than good.

What sort of mechanisms might help overcome these problems? Perhaps the first requirement would be to make it normal and professionally respectable for doctors to pass on complaints to their colleagues - a part of the ordinary professional process of self-audit or quality control: explicit advice to this effect in the GMC's blue book would help. Of course the process would have to be dealt with tactfully, and one important rule of thumb would be to be very wary about accepting the patient's account as being the end of the matter - it may or may not be accurate. The role of the informing doctor would be to pass on the fact and substance of a complaint (assuming that the patient wished this to happen), rather than to act as prosecuting counsel or judge. However, as part of the mutual objective of trying to help the patient some effort should surely be made by both doctors to remedy matters - in practice a meeting between the patient and doctor complained about can usually lead to resolution.

Nonetheless, it is undeniably difficult, for many of us, to pass on complaints about them to our colleagues, face to face (or even over the telephone or in writing). Rather than letting this simple fact of human nature result in the complaint being ignored should there not instead be a mechanism for confidential or perhaps even anonymous reporting of such complaints about medical colleagues? One possibility would be to extend the existing hospital mechanism of 'three wise doctors' to whom suspected mental illness, alcohol or drug abuse in a colleague is reported, so as to include the reporting of complaints by patients or colleagues. Similar arrangements could be instituted for general practice, perhaps by appointing 'three wise doctors' from the local medical committee.

The 'three wise doctors' would then pass on the substance of the complaint and invite the doctor concerned to give his or her account of the matter and how it was to be dealt with. If in particular cases the 'three wise doctors' felt that the complaint seemed justified and that the doctor complained about was not taking appropriate action to resolve it, or if they had received a series of apparently justified complaints that indicated to them that the doctor concerned was behaving in an unprofessional manner, then they should be able to report the matter to the GMC, even though serious professional misconduct in the GMC's sense of infamous conduct in a professional respect was not suspected. Again an existing mechanism could be adapted: the GMC could simply be given the statutory power to address itself to ordinary professional misdemeanours rather than as at present having to confine itself to 'serious professional misconduct' (which in ordinary parlance means extremely serious professional misconduct - 'infamous conduct').

The GMC would then notify the doctor of the complaint, invite his or her comments, and only take further action if there seemed a prima facie case that the complaint was justified (for there is undoubtedly a category of unjustified complaints, some of them made because the complainant is psychologically ill, some simply malicious and some made by those who are addicted to complaining). However if there was a prima facie case of unprofessional behaviour - and this should include any reports made by committees of 'three wise doctors' - then the GMC would investigate it with a view not to punishment but to resolving matters wherever possible, both for the individual patient if a complaint were shown to be jusified, and for the benefit of future patients. Thus the GMC might require the doctor to meet the patient and discuss matters further, and/or to apologise, and/or to attend a relevant programme of re-education or re-training so as to remedy any defect identified. If, for example, the complaint was one of recurring rudeness to patients, or recurring unpleasantness, then a course in communications and consultation skills or a Balint group or even involvement in some form of psychotherapy might be the appropriate remedial action. On the other hand if the complaint related to a doctor's technical skills then the appropriate remedy might be to take the relevant clinical re-training.

One result of such increased professional selfscrutiny would almost certainly be that as doctors we would have to confront more complaints, some unjustified, some not serious. However, there can be little real doubt that if we have been the cause of a patient's complaint it is better that we know about it, whether to clear up misunderstandings, or to apologise when we have been in the wrong, or to change our practice or our style of practice when complaints are recurrent. In addition it would enable us to make it quite clear to patients who make unjustified complaints why we believed they were unjustified.

Such a development might well prove uncomfortable. But as well as helping improve our services to our patients, it might also help avert the development in Britain of the American way of dealing with complaints about doctors - notably an ever greater tendency to litigate.

\section{References}

(1) General Medical Council. Professional conduct and discipline: fitmess to practise. London: GMC, 1989: 17.

(2) General Medical Council. Annual Report, 1989. London: GMC, 1990. 